\title{
Correction to: Renewable energy-economic growth nexus revisited for the USA: do different approaches for modeling structural breaks lead to different findings?
}

\author{
Umit Bulut $^{1}$ (D) Muhammad Shahbaz ${ }^{2,3} \cdot$ Xuan Vinh Vo ${ }^{4}$
}

Published online: 5 February 2022

๑) Springer-Verlag GmbH Germany, part of Springer Nature 2022

\section{Correction to: Environmental Science and Pollution Research https://doi.org/10.1007/s11356-021-17684-z}

Muhammad Shahbaz is not affiliated to COMSATS University of Islamabad.

The Original article has been corrected.

Publisher's note Springer Nature remains neutral with regard to jurisdictional claims in published maps and institutional affiliations.

The online version of the original article can be found at https:// doi.org/10.1007/s11356-021-17684-z

Umit Bulut

ubulut@ahievran.edu.tr

Muhammad Shahbaz

muhdshahbaz77@gmail.com

Xuan Vinh Vo

vxvinh@yahoo.com

1 Department of Economics, Faculty of Economics and Administrative Sciences, Kirsehir Ahi Evran University, Kirsehir, Turkey

2 School of Management and Economics, Beijing Institute of Technology, Beijing, China

3 Institute of Business Research, University of Economics, Ho Chi Minh City, Vietnam

4 Institute of Business Research and CFVG, University of Economics, Ho Chi Minh City, Vietnam 